\title{
Evaluation Study on grid-connected PV System at University of Malaya
}

\author{
Sam Koohi Kamali \\ Dept. of Electrical Engineering \\ University of Malaya \\ Lembah Pantai, 50603 Kuala Lumpur. \\ Email:sam.koohi@gmail.com
}

\author{
Dr.Saad Mekhilef \\ Dept. of Electrical Engineering \\ University of Malaya \\ Lembah Pantai, 50603 Kuala Lumpur. \\ Email:saad@um.edu.my
}

\begin{abstract}
This paper presents the complete design of a photovoltaic installation that may be either used for internal electric consumption or for sale using the renewable energy incentive program by the state of Malaysia (SURIA 1000 and so on.). Moreover in this article an economic and environmental study is carried out on PV solar energy installations connected to the Malaysian electrical grid system. The study has been performed on construction situated in the city of Kuala Lumpur (with an average irradiation value approximately equal to 5.4 $\mathbf{k W h} / \mathrm{m}^{2} / \mathbf{d}$ ) based on an analysis of the technical and financial viability of a grid connected PV systems. Initially, the study is performed; proposing different scenarios where different values of interest rates and initial costs incentives applied. The following parameters are used to determine the profitability of a PV structure: the Net Present Cost (NPC), Renewable Fraction (RF) and Lifetime. Furthermore, the environmental benefits of PV systems connected to the grid have been evaluated.
\end{abstract}

\section{INTRODUCTION}

\section{A. Renewable Energy Power Purchase Agreement}

REPPA is a legislation issued by the Malaysian government dealing with the power purchase agreement between power utility TNB and private investors for renewable energy projects. Under REPPA, renewable energy electricity producers are given a license for a period of 21 years, which is effective from the date of commissioning of the plant [1].

\section{B. Tax and Duty Policies}

Since the national budget in 2000, renewable energy technologies have been given additional incentives in the form of tax relief and waivers of import duties. The incentives are part of the package of government measures designed to encourage the implementation of renewable energy projects as part of the Fifth Fuel Policy [1].

\section{Small Renewable Energy Power Program}

The Small Renewable Energy Power Program (SREP) was launched in May 2001 to enhance the use of renewable energy resources in the power sector. The objective is to facilitate the implementation of small grid-connected, renewable power plants. The SREP target is to connect to $500 \mathrm{MW}$ of renewable power plants to the national grid within the framework of the Renewable Energy Power Purchase Agreement [1].

The energy demand of Engineering Tower (the case of study in this paper) is on average around of a commercial building [9], with an annual power consumption ranges from 800 to 900 $\mathrm{kWh} / \mathrm{d}$ [8]. Moreover some policies should be taken into account toward the optimization of electricity consumption at engineering tower such as optimization of current consumption, reduction of electricity demand and feasibility of PV installation [4].

Average annualized energy consumption of Engineering Tower demonstrates that if the Malaysian State as a whole is to become more environmentally sustainable while a strong need exists for the Campus and teaching facilities, it seems necessary for "University of Malaya" to decrease the annual energy consumption and a reduction in greenhouse gas emissions at Engineering Tower as well as other faculties through RES and efficient measuring [3].

The implementation of energy efficiency measures and audit is well studied before and is not considered in this paper [8], moreover we only consider PV RES because of some limitations which we have due to the location and structure of engineering tower.

As some studies of successful RES installations have been carried out on many non-educational enterprises before, the installations may be split into two configuration categories, hybrid and autonomous supply [3].

Whereas, the amount of power needs at Engineering Tower located in Kuala Lumpur is equally comparable with commercial building as well as it is categorized in tariff B [8], we have identified only one technical and several economical case studies in the literature examining the feasibility of RES in grid-connected commercial building (Engineering Tower), considering the average amount of using energy. A nontechnical study reports the successful installation of a large 674 $\mathrm{kW}$ PV in a large-scale accommodation in Hawaii, claiming a $30 \%$ renewable fraction [3].

Modelling software for distributed power was used to examine the research aims is HOMER (a public domain software produced by National Renewable Energy Laboratory, 
US) [3]. Thus, according to the latest researches which have been mentioned above, already a suitable tool for the evaluation of RES is HOMER software that can assess the feasible combinations on the basis of most important economical factors.

\section{HOMER}

HOMER is primarily an optimisation software package which simulates varied RES system configurations and scales them on the basis of NPC. HOMER firstly assesses the technical feasibility of the RES system (i.e. whether the system can adequately serve the electrical and thermal loads and any other constraints imposed by the user). Secondly, it estimates the NPC of the system, which is the total cost of installing and operating the system over its lifetime [3]. The project lifespan was taken as 20 years.

\section{A. Climate data}

The solar radiation in Malaysia is high by world standards. Even in Kuala Lumpur, a PV system receives 30\% more energy than an equivalent system in Germany. Solar radiation varies from its lowest in the Klang Valley (Kuala Lumpur, Petaling Jaya) to Penang (Georgetown, northwest coast) and Kota Kinabalu (East Malaysia), where the highest values have been measured. Subject to location, a typical PV installation in Malaysia would produce about $900-1400 \mathrm{kWh} / \mathrm{kWp}$. An installation in Kuala Lumpur would yield around 1000-1200 $\mathrm{kWh} / \mathrm{kWp}$ per year [1].

The strength of solar radiation is the primary consideration in selecting location for PV installation. The electricity output of a PV array is directly proportional to the radiation input. Local climatic and environmental factors such as temperature extremes, humidity, precipitation, and wind will constrain the output of PV array [5].

Nevertheless, these are all secondary effects when compared with insolation intensity. The total yearly insolation changes with latitude at different locations. Photovoltaic performance calculation requires the incoming solar radiation, ambient air temperature and local humidity [5].The meteorological data such as air temperature, humidity, solar radiation, precipitation, and so on, are extracted by finding the latitude ( 3,7 ', North) and longitude (101 , 39', East) of Engineering Tower [7] as well as applying them into the HOMER solar resources inputs. By having the latitude and longitude of a location, this software can find all data via internet to obtain the monthly local radiation, temperature and humidity data as shown in Fig.1.

\section{B. Assessment criteria}

Net present cost (NPC) represents the life cycle cost of the system. The calculation assesses all costs occurring within the project lifetime, including initial set-up costs (IC), component replacements within the project lifetime, maintenance and fuel. Future cash flows are discounted to the present. HOMER calculates NPC according to the following equation [3]:
$N P C(\$)=\frac{T A C}{C R F}$

where TAC is the total annualised cost $(\$)$ (which is the sum of the annualised costs of each system component). The capital recovery factor $(\mathrm{CRF})$ is given by [3]:

$$
C R F=\frac{i(1+i)^{N}}{(1+i)^{N}-1}
$$

where $\mathrm{N}$ is the number of years and $\boldsymbol{i}$ is the annual real interest rate $(\%)$.

HOMER assumes that all prices escalate at the same rate, and applies an 'annual real interest rate' rather than a 'nominal interest rate'. All costs are therefore calculated in constant dollars. This method allows 'inflation' to be factored out of the analysis. The overall annual (real) interest rate $\boldsymbol{i}$ in the simulations was taken to be $2.08 \%$ which was applied over a project lifetime assessed as 20 years [6].

As a basic knowledge for optimizing either system neglecting the HOMER software, for affiliating with the logic of calculations which is behind of the optimization, we briefly point out to the calculations as follow. The Net Present Value (NPV) and Pay-Back Period (P) have been used to valuate the PV systems. A number of terms are defined that are needed to calculate these two values here in the paper. The size of the investment and initial costs (S): This is the initial cost of the grid connected PV system. It can be expressed by [2]:

$S=C_{g e n}+C_{i n v}+C_{i n s t}-C_{s u b}=C_{s y s t e m}-C_{s u b}$

This includes the cost of the generator $C_{g e n}$, the cost of the inverter $C_{i n v}$, the costs of the installation $C_{\text {inst }}$ (including supporting structures, wiring, protective elements, engineering, etc.). The sum of these costs is the system cost $C_{\text {system }}$ Likewise, $C_{s u b}$ is the possible quantity of financial subsidy on the initial cost. The duration of the investment $(\mathrm{N})$, is the service life of the installation in years. Net Cash Flow for year $\boldsymbol{j}$ $\left(Q_{j}\right)$; the net cash flow, for a certain instance in time is the difference between the cash input generated by the investment and the payment or cash output the investment requires. This is expressed in bellow equation [2]:

$$
\begin{aligned}
& Q_{j}=(\text { Cash Input })_{j}-(\text { Cash output })_{j} \\
& =\left(p_{b} \cdot E_{\text {PVaut }}+p_{s} \cdot E_{\text {PVinj }}\right)-\left(C_{\text {O\&M }}+C_{\text {ins }}+C_{\text {Fin }}\right)
\end{aligned}
$$

$p_{b}$ and $p_{s}$ are the prices of the energy bought from and sold to the utility respectively. $E_{\text {PVaut }}$ is the annual energy generated by the PV system connected to the grid that is auto consumed (and which is therefore not bought from the grid) and $E_{P V i n j}$ is 


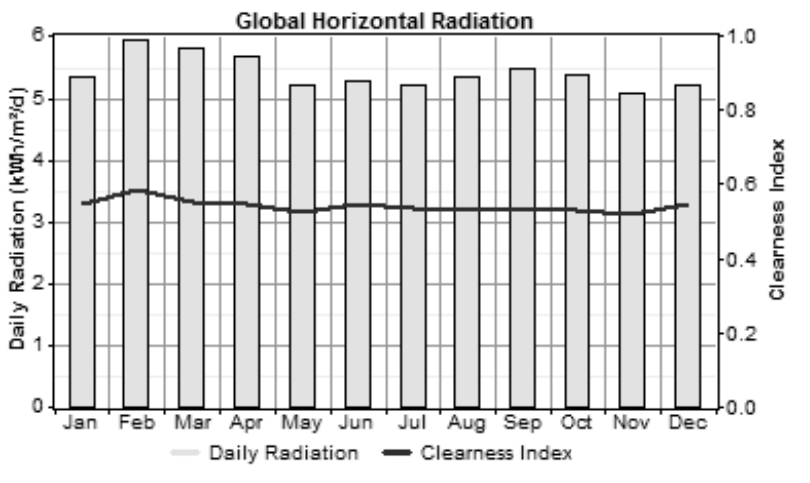

Figure1.Faculty of Engineering Solar Resources inputs

the generated energy injected into the grid annually. Note that if all the produced energy is sold, the most favourable situation is resulted, like a permitted system in Spain. Furthermore, $C_{O \& M}, C_{\text {ins }}$ and $C_{F i n}$ are the annual costs attributed to the operation and maintenance, insurance and financing, respectively. In Spain, where all the energy can be sold, $E_{\text {PVaut }}=0$ and Equ. 4 becomes [2]:

$$
\begin{aligned}
Q_{j} & =(\text { Cash Input })_{j}-{\text { (Cash output })_{j}} \\
& =\left(p_{s} . E_{P V i n j}\right)-\left(C_{O \& M}+C_{i n s}+C_{F i n}\right)
\end{aligned}
$$

It should be taken into account that the income and expenditures may vary from year to year due to inflation. For PV systems connected to the grid the maintenance costs and insurance increase with inflation. However the income due to the sale of the energy does not necessarily have to increase, the sale price as mentioned previously in the introduction depends on the average electricity tariff. The price of electricity can vary due to market results (based on the pool, and bilateral contracts). Bearing this in mind, the economical analysis offered in this paper assumes that the sale price does not change throughout the life cycle of the installation. Equ.5 taking into account the updating of annual costs becomes [2]:

$$
\begin{aligned}
Q_{j}= & (\text { Cash Input })_{j}-(\text { Cash output })_{j} \\
& =\left(p_{s} . E_{P V i n j}\right)-\left[\left(C_{O \& M}+C_{i n s}\right)(1+g)^{j}+C_{F i n}\right]
\end{aligned}
$$

where Inflation rate $(\mathrm{g})$ is the accumulative inflation rate.

In order to compare investments it is necessary to consider the same instances in time. If the cash flow is over various years, they should all be considered in the same instances in time (normally at the start of the investment), in this way the different investments can be compared using the Nominal Interest Rate and the Net Present Value. If the value of $\boldsymbol{i}$ or $\boldsymbol{g}$ are time independent, the NPV of the investment is given as [2]:

$$
N P V=-S+\frac{Q_{1}}{(1+i)}+\frac{Q_{2}}{(1+i)^{2}}+\ldots+\frac{Q_{N}}{(1+i)^{N}}=-S+\sum_{J=1}^{N} \frac{Q_{j}}{(1+i)^{j}}(7)
$$

The NPV establishes, as an acceptance criterion for the investment, that the generated benefits will be greater than costs. That is to say that the NPV should be as large as possible and always positive. The Pay-Back Time (P) is the number of years needed to make the NPV of the cash flow up to the present moment, to be equal to the initial outlay of the investment. This is expressed as [2]:

$$
-S+\sum_{J=1}^{N} \frac{Q_{j}}{(1+i)^{j}}=0
$$

According to this method of analysis, the shorter the PayBack Time is, the better the investment. This is a criterion which values the availability more than the profitability and does not take into account the cash flow generated after the recuperation period.

NPC estimation in HOMER also takes into account salvage costs, which is the residual value of power system components at the end of the project lifetime. For this calculation, HOMER assumes a linear method of depreciation, where the salvage value of a component is directly proportional to its remaining life. It also estimates salvage value based on replacement cost rather than initial capital cost. The equation to calculate salvage value $(\mathrm{S})$ is given as [3]:

$S(\$)=C_{r e p} \frac{R_{r e m}}{R_{\text {comp }}}$

where $C_{r e p}$ is the replacement cost of the component (\$), $R_{r e m}$ is the remaining life of the component ( $\mathrm{t})$ and $R_{\text {comp }}$ is the lifetime of the component $(t)$. The renewable fraction $(R F)$ is the portion of the system's total annual electrical production originating from renewable power sources. It is calculated by dividing the total renewable power production by the total energy consumed.

\section{System constraints}

The capacity shortage fraction (CSF) is the fraction of the total load plus operating reserve that the system fails to supply (i.e. allowable blackout). A CSF of $0 \%$ of hourly load was chosen for all grid-connected simulations, as the grid can be considered as an infinite capacity storage reserve (blackouts are still possible, but for a very small percentage of the time). Simulations examining a renewable energy-only configuration had a $2 \%$ CSF, as recommended by Givler and Lilienthal. The operating reserve constraint (commonly called 'spinning reserve') is the additional reserve capacity required for a system to account for sudden increases in the electric load or sudden decreases in the renewable power output. It was set at $10 \%$ as recommended by Cotrell and Pratt. Higher reserves were specified when using the renewable output. The higher reserve is required due to the inherent variability in the RES output, and was set at $25 \%$ for PV [3]. 


\section{DATA INPUTS}

Data for the load profile was accessed from University of Malaya maintenance office shows that the annual average energy consumption for the engineering tower is $80 \mathrm{kWh} /$ day [19]. Peak load for a day is $9.5 \mathrm{~kW}$ Fig. 2, displays a smooth daily energy load profile, with some significant peaks or fluctuations between 9 am to $6 \mathrm{pm}$.

\section{A. System configuration}

A hybrid energy system generally comprises RES components working in conjunction with a non-renewable power generating system and storage modules. For the purposes of this paper, the non-renewable power source is the electricity grid; for bearing in mind, Fig. 3 illustrates that grid electricity can flow in both directions through the $\mathrm{AC}$ bus. Thus, when RES supply is insufficient, grid electricity is bought from the grid, or when in excess, is sold back to the grid via a sellback arrangement with the grid supplier. The case-study University of Malaya purchased electricity from its supplier at a discount rate of $\$ 0.05 / \mathrm{kWh}$ when the case study was conducted in 2008 for the purposes of this paper; a base electricity sellback price to the supplier was also set at $\$ 0.05 / \mathrm{kWh}$, with a sensitivity analysis performed for a range of sellback prices [3].

\section{B. Environmental data}

As it was shown in the previous part Hourly solar data was extracted by finding the latitude ( 3 , 7 ', North) and longitude (101 , 39', East) of Engineering Tower [7] as well as applying them into the HOMER solar resources inputs. By having the latitude and longitude of a location, this software can update all data via internet to obtain the monthly local radiation, temperature and humidity data.

\section{Photovoltaic array generator}

Once the convenience of having a solar photovoltaic installation has been decided, we have to consider the limited economic funds available to the Centre. Thus, instead of choosing a traditional design based on power from generators and inverters we seek a more flexible design method that takes into account all the parameters that can have an influence on: performance, production, financial data, available subsidies, remuneration for selling electricity, taxes applied to the remuneration, annual quota in concept of repayment once the electricity sales income is discounted, and etc. In this way, our automated calculation of the solar photovoltaic installation generates numerous advantages compared to traditional design methods [4].

\section{Photovoltaic data inputs}

The photovoltaic (PV) output in $\mathrm{kWp}$ is all that is required for sizing and it is assumed that output is linearly proportional to incident radiation.

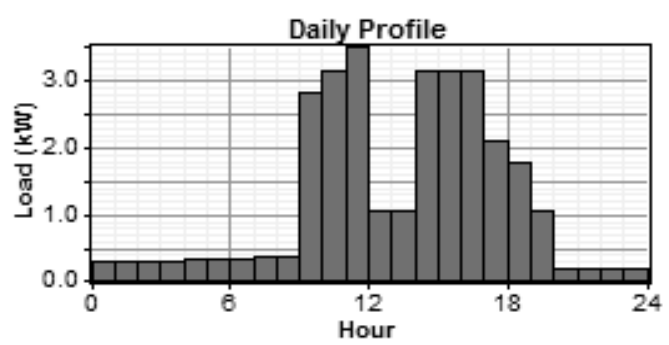

Figure 2. Daily load profile extracted from maintenance office

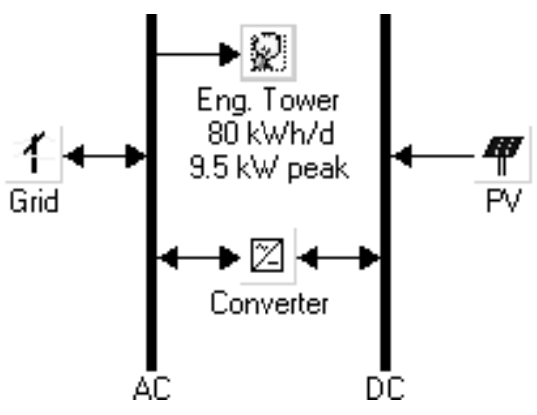

Figure 3. The system energy flow diagram with AC/DC buses

Other relevant factors such as PV technology type or area size $\left(\mathrm{m}^{2}\right)$ are not required. A standard cost of $\$ 10,000 / \mathrm{kW}$ of PV power produced were used with an operational and maintenance cost of $\$ 10 /$ year $/ \mathrm{kW}$. Four PV panel with different sizes and models were considered at $195 \mathrm{~kW}$. The derating factor to compensate for reduction in efficiency due to temperature, dust and wiring losses was 0.9. Lifetime of the panels was taken to be 25 years. Maximum power point tracking (MPPT) was taken as a standard installation [3].

In order to analyse various scenarios, a number of values for the subsidy are considered: $0,50,60,65 \%$ and etc by sensitive analysis. In all cases, the payment of the whole installation (subsidy included) is considered at the initial stage of the investment.

\section{E. Converter}

The applied method of electricity storage is defined on the basis of the grid-connected configuration. The grid itself is as a virtual store of electricity, when excess electricity produced by a RES is sold back to the grid.

The initial cost (IC) for a converter of $\$ 1000 / \mathrm{kW}$ was chosen and $\mathrm{O} / \mathrm{M}$ of $\$ 0 / \mathrm{kW}$, with a lifetime of 15 years and efficiency of $90 \%$, as recommended by Givler and Lilienthal. Converter sizing is roughly in proportion to the size of the load it serves. Sizing for the case-study converters therefore ranged from 40 and $156 \mathrm{~kW}$ [3].

\section{F. Battery}

For having a comparison between the system consist of grid as a virtual storage device as well as a stand-alone system by using the batteries we configure another system simulation by HOMER, in this way the consequences show that the system 
with battery have no economical justification in front of the number of PV panels installed and the building electricity consumption as well as the initial costs which is caused.

\section{HOMER ANALYSIS}

\section{A. Grid/RES hybrid}

The HOMER simulation result shows that using of 870 numbers of PV modules which totally has almost $195 \mathrm{kWp}$ worthwhile of energy production on the engineering tower roof area equal to $1417.5 \mathrm{~m}^{2}$ is technically viable, with an NPC of $\$ 62.5 \mathrm{~K}$, further the achieved RF in this configuration equals to $99 \%$, addition of battery and rectifier are not required in this configuration, as the grid network acts as the backup reserve and the loads are AC.

As it is shown in Fig.4, The net present cost value with the assumption of interest rate of $2.08 \%$ and the capital incentive rates of $50 \%$ for both of the PV modules and converter installation, as well as the sell back rate of $0.25 \$ / \mathrm{kWh}$ beside of zero maintenance cost results 20 years project lifetime. This result leads us to be more motivated for investing on the project.

For more detailed analysis you can find the categorized costs on Table.1, as you can see the minus sign which is applied to NPC is a reverse sign allocated by the HOMER which shows at the beginning of the project with annualizing of all costs, the investment is profitable. The HOMER simulation shows that in Grid/RES hybrid configuration, the amount of emissions with the assumption that the taxes are zero can be reduced dramatically.

\begin{tabular}{|l|c|r|c|r|r|c|}
\hline \multirow{2}{*}{ Component } & Capital & Replacement & O\&M & Fuel & Salvage & \multicolumn{1}{c|}{ Total } \\
\cline { 2 - 7 } & \multicolumn{1}{c|}{$(\$)$} & $(\$)$ & $(\$)$ & $(\$)$ & \multicolumn{1}{c|}{$(\$)$} & \multicolumn{1}{c|}{$(\$)$} \\
\hline PV & 975,000 & 0 & 0 & 0 & 0 & 975,000 \\
\hline Grid & 0 & 0 & $-1,115,500$ & 0 & 0 & $-1,115,500$ \\
\hline Converter & 78,000 & 0 & 0 & 0 & 0 & 78,000 \\
\hline System & $1,053,000$ & 0 & $-1,115,500$ & 0 & 0 & $-62,500$ \\
\hline
\end{tabular}

Table 1.Categorized cost with the NPC calculation

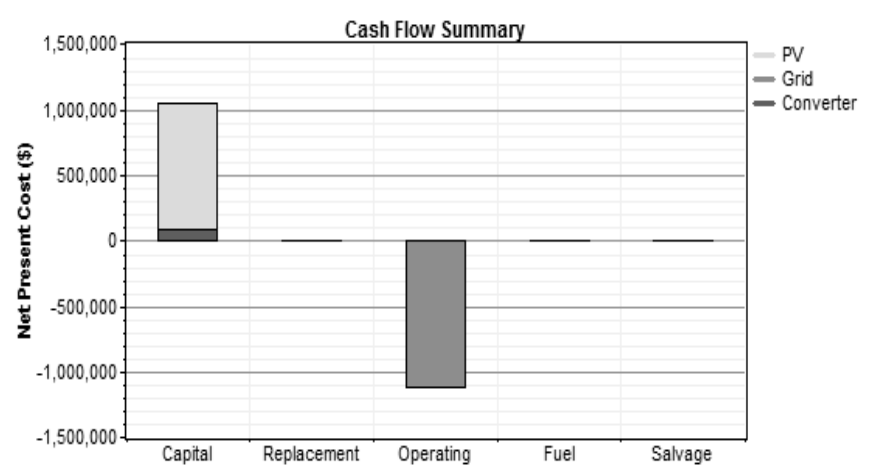

Figure 4. Net Present Costs Evaluation by the cash flow summery

According to Table.2, in comparison with the grid only configuration which the amount of emissions were equal to $663 \mathrm{~g} / \mathrm{kWh}$ (for $\mathrm{CO} 2$ ), $2.74 \mathrm{~g} / \mathrm{kWh}$ (for sulfur dioxide) and
$1.34 \mathrm{~g} / \mathrm{kWh}$ (for Nitrogen oxides) [9], we find out that practically this volume of emissions are removable.

\section{B. Sensitivity Analysis of Grid/RES Configuration}

Considering the different interest rates, initial costs incentives, sellback rates and project lifetime, the simulation results varies from one to another. For example, by considering of the interest rate of $2.08 \%$, initial cost incentives of $50 \%$ and the project life time of 20 years the resulted simulation with the amount of sellback prices around of the net metering $(0.08 \$ / \mathrm{kWh})$ is not economical due to the NPC of $\$ 696 \mathrm{~K}$ which shows a big amount of money debiting at the starting of project, accordingly the results of this parameter combination is illustrated on Table.3.

Another combination between the parameters which seems to be feasible is investigating the impact of interest rate changing due to the inflation or banking policies. By this consideration other parameters can be controlled by HOMER optimization options toward finding a feasible as well as profitable solution. For instance, if the interest rate because of any reason is to be changed to $6 \%$ then the project lifetime and the sellback price should be set on 25 years and $0.3 \$ / \mathrm{Kwh}$ respectively.

Although the incentives rate assume to be $50 \%$ however the simulation result shows an incoming NPC about $\$ 1.6 \mathrm{~K}$ at the beginning of the project by transferring the costs over 25 years to the first year, in Fig.5 the NPC of this structure is demonstrated as well as on Table.4, the categorized annualized costs for each part of the mentioned system is obviously considerable.

\section{Summary}

By substituting of different values of parameters such as interest rate, project lifetime, sellback rate and initial cost incentives, we find out that there is a direct relationship among

\begin{tabular}{|l|r|}
\hline \multicolumn{1}{|c|}{ Pollutant } & Emissions (kg/yr) \\
\hline Carbon dioxide & $-182,320$ \\
\hline Carbon monoxide & 0 \\
\hline Unburned hydocarbons & 0 \\
\hline Particulate matter & 0 \\
\hline Sulfur dioxide & -753 \\
\hline Nitrogen oxides & -368 \\
\hline
\end{tabular}

Table2.Emissions after the Grid/RES simulation evaluation

\begin{tabular}{|l|c|r|r|r|r|c|}
\hline \multirow{2}{*}{ Component } & Capital & Replacement & O\&M & Fuel & Salvage & \multicolumn{1}{c|}{ Total } \\
\cline { 2 - 7 } & \multicolumn{1}{c|}{$(\$)$} & $(\$)$ & $(\$)$ & $(\$)$ & \multicolumn{1}{c|}{$(\$)$} & \multicolumn{1}{c|}{$(\$)$} \\
\hline PV & 975,000 & 0 & 0 & 0 & 0 & 975,000 \\
\hline Grid & 0 & 0 & $-356,960$ & 0 & 0 & $-356,960$ \\
\hline Converter & 78,000 & 0 & 0 & 0 & 0 & 78,000 \\
\hline System & $1,053,000$ & 0 & $-356,960$ & 0 & 0 & 696,040 \\
\hline
\end{tabular}

Table 3.Categorized cost with the NPC calculation with the sellback price of $(0.08 \$ / \mathrm{kWh})$ 


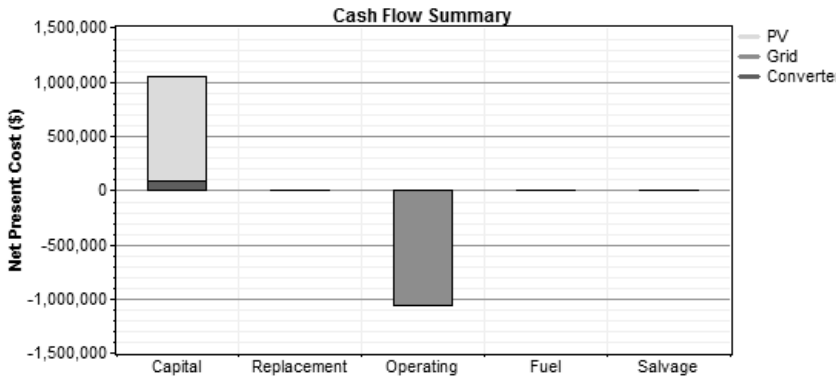

Figure5. Net Present Costs Evaluation by the cash flow summery due to the interest rate changing to $6 \%$

\begin{tabular}{|l|r|r|r|r|r|r|}
\hline \multirow{2}{*}{ Component } & Capital & Replacement & \multicolumn{1}{c|}{ O\&M } & Fuel & Salvage & \multicolumn{1}{c|}{ Total } \\
\cline { 2 - 7 } & \multicolumn{1}{|c|}{$(\$)$} & $(\$)$ & \multicolumn{1}{c|}{$(\$)$} & $(\$)$ & \multicolumn{1}{c|}{$(\$)$} & \multicolumn{1}{c|}{$(\$)$} \\
\hline PV & 975,000 & 0 & 0 & 0 & 0 & 975,000 \\
\hline Grid & 0 & 0 & $-1,054,598$ & 0 & 0 & $-1,054,598$ \\
\hline Converter & 78,000 & 0 & 0 & 0 & 0 & 78,000 \\
\hline System & $1,053,000$ & 0 & $-1,054,598$ & 0 & 0 & $-1,598$ \\
\hline
\end{tabular}

Table 5. Categorized cost with the NPC calculation cost calculation with the sellback price of $(0.3 \$ / \mathrm{kWh})$ and project lifetime of $25 \mathrm{yrs}$ by changing of interest rate to $6 \%$

the increasing of NPC and the interest rate, while this relationship is available between the project lifetime and NPC conversely.

Based on the extended ranges of government's subsidies, by growing up of these facilities the initial cost is to be decreased dramatically, for example by rising of the subsidies, the initial cost incentives, and the amount of project lifetime goes to be shorten, moreover by this assumption the interest rate can be assumed more than before.

As another factor, the agreed rate of electricity sellback price seems to be very important meanwhile this rate is identified by the government, further by increasing of this parameter the project lifetime as well as the dedicated subsidies to the plan can be supposed lower by the state decision makers. Furthermore the sellback and incentive rates are the evaluable parameters by the lawyer while finding the balanced amount of them is a critical objective.

\section{Renewable Energy System only}

Performing the HOMER simulation with stand-alone combination has been evaluated in several amounts of parameters and all the result illustrates that there is not available any feasible economical solution by this type of system. In the other word the role of sellback rate to the utility is completely prominent. For example, setting all the subsidy rates to $0.1(90 \%$ commercial aid at the beginning of project that seems to be impossible by the government with such amount of load) results the NPC of $\$ 214.9 \mathrm{~K}$ debiting money, moreover the NPC evaluation of this configuration is illustrated in Fig.6, as well as categorized cost is calculated in Table.5, It should be noticed that systems like this in the practical world is not viable in the other word this calculation is only done to specify the unavailability of this system while the parameters are extremely optimistic.

\section{CONCLUSION}

The implemented simulations towards designing an optimized system with an economical viability lead us to compare and simulate two types of system configuration which are Grid/RES and RES only.

In the first case we studied the system while it was connected to the grid moreover grid played the role of a virtual storage resource of energy instead of battery, in the other word in this system the exceeded produced energy by the photovoltaic source can be sold to the utility.

In this economical evaluation and optimization we took into account some definitions such as interest rate, sellback price, and incentive or subsidy rate and the project lifetime that each of them can be impressed by others.

As a whole rule, the evaluation of systems is encountered by many limitations and considerations. For example, the subsidy, sellback and interest rates are the parameters (as it was mentioned before) that should be identified in the long term planning by the government decision makers on the basis of predefined policies. In the supposed system HOMER could estimate an economical system based on the current values of parameters except the sellback price that should be changed to $0.25 \$ / \mathrm{kWh}$ until this system to be economically feasible. We also can minimize the sellback price by increasing of project lifetime in the other hand side, the NPC of positive value as an income at the first year shows that the real lifetime of the project is lower than 20 years.

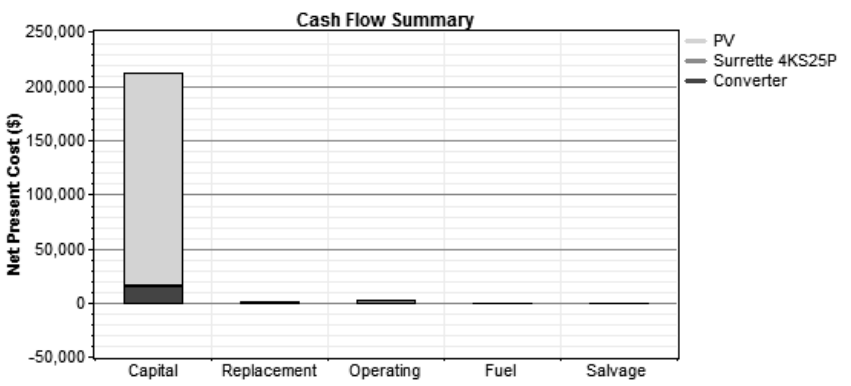

Figure 6. Net Present Costs Evaluation by the cash flow summery for RES configuration by optimistic set of incentives

\begin{tabular}{|l|c|r|r|r|r|c|}
\hline \multirow{2}{*}{ Component } & Capital & Replacement & O\&M & Fuel & Salvage & Total \\
\cline { 2 - 7 } & \multicolumn{1}{c|}{$(\$)$} & $(\$)$ & $(\$)$ & $(\$)$ & $(\$)$ & $(\$)$ \\
\hline PV & 195,000 & 0 & 0 & 0 & 0 & 195,000 \\
\hline Surrette 4KS25P & 990 & 1,377 & 2,193 & 0 & -267 & 4,293 \\
\hline Converter & 15,600 & 0 & 0 & 0 & 0 & 15,600 \\
\hline System & 211,590 & 1,377 & 2,193 & 0 & -267 & 214,893 \\
\hline
\end{tabular}

Table 4. Categorized cost with the NPC calculation for the most optimistic RES only configuration

Another type of configuration was evaluated is called standalone system, such a system can not be viable because there is no economical feasibility for that due to the high initial costs while at this optimization the parameter's values is assumed to be most optimistic. For instance the incentive rate of $90 \%$, which is not realistic with such amount of installation wattage, 
is considered. Consequently, this stand-alone system identified the prominent role of the grid connection composition, as well as it shows that the sellback rate price is defined as a very important factor with respect to design a beneficial optimization.

\section{ACKNOWLEDGMENT}

These authors wish to acknowledge the supports for this research paper received from the Faculty of Engineering located at University of Malaya.

\section{REFERENCES}

[1] AUSTRALIAN BUSINESS COUNCIL FOR SUSTAINABLE ENERGY, August 2005. An overview of the energy systems, renewable energy options, initiatives, actors and opportunities in Malaysia.

[2] BERNAL-AGUSTÍN, J.L. and DUFO-LÓPEZ, R., 2006. Economical and environmental analysis of grid connected photovoltaic systems in Spain. Renewable Energy, 31(8), 1107-1128.

[3] DALTON, G.J., LOCKINGTON, D.A. and BALDOCK, T.E., 2009. Feasibility analysis of renewable energy supply options for a gridconnected large hotel. Renewable Energy, 34(4), 955-964.

[4] FERNÁNDEZ-INFANTES, A., CONTRERAS, J. and BERNAL AGUSTÍN, J.L., 2006. Design of grid connected PV systems considering electrical, economical and environmental aspects: A practical case. Renewable Energy, 31(13), 2042-2062.

[5] GONG, X. and KULKARNI, M., 2005. Design optimization of a large scale rooftop photovoltaic system. Solar Energy, 78(3), 362-374.

[6] Available on: http://www.bnm.gov.my/index.php?ch=12\&pg=622, $15^{\text {th }}$ May 2009 at $10 \mathrm{am}$.

[7] PAGE NATION, 2009-last update, faculty of engineering, university of malaya.Available:http://my.pagenation.com/kul/Faculty $\% 20$ of $\% 20$ Engin eering,\%20University\%20of\%20Malaya 101.6553 3.1186.map [March].

[8] S/O SINNADURAI, R., 2003. Energy Audit and Energy Costs Report Phase Two. Master of Engineering dissertation edn. University of Malaya, Faculty of Engineering.

[9] UNIVERSITY OF MALAYA, MAINTENACE OFFICE, 2008. Daily Load Profile. 